\title{
Emergence of living language: ontogeny- phylogeny framework and other parallels of linguistics and biology
}

Michaela Zemková*

Charles University in Prague, Faculty of Science, Department of Philosophy and History of Science, Viničná 7, Praha 2, 12000

Received June 25, 2018; Accepted August 23, 2018

Abstract: Although language is something deeply embedded in our nature, the question of its origin is of the same order as the misty question of the origin of life. I point out that the core of the problem can be rooted in the dichotomy between language and speech, similar to the dichotomy of genotype and phenotype in biology. Following the ontogeny-phylogeny framework, I propose that studies of language ontogeny, especially its early stages, can bring a new understanding to language, same as the study of communication in non-human primates..

Keywords: genotype $\bullet$ phenotype $\bullet$ ontogeny-phylogeny $\bullet$ origin of language $\bullet$ origin of life $\bullet$ speech development

(c) Sciendo

\section{Introduction}

\section{Language and life}

One common quality of human and genetic texts is that they both share a linear structure: it is possible to convert them into a linear sequence of symbols. Since these linear expressions of genomes and languages represent human constructs - led by the same tendency to transform complex dynamic structures into inert intelligible and unambiguous records, we should rather build the analogy between life and language. A sequence of nucleotides is in no way exhaustive with respect to a DNA molecule, and a text can never be an entire and complete reproduction of speech. In spite of this, if we would like to find an analogy on the level of the texts (DNA, RNA, proteins and human texts), then we should not search for it in sequences of symbols but in the process of reading them. Neither human texts nor genomic sequences are read mechanically, but they are interpreted according to the reader's evolutionary/cultural history and changing context.

Hence, the analogy between human languages (objects of linguistics) and living beings (objects of natural sciences) actually does not reside in comparisons of sequences of symbols or mathematically defined features, nor does it lie in questions regarding whether the language faculty is "written" in any manner in genomic information or not. Contrariwise, the analogy points out to the fact that both are living, autonomous, and self-creating structures interpreting their surrounding world actively; the same can be stated regarding the enigma of their origin. In modern biology, there is a trend to reduce as many living phenomena as possible into linear sequences. Neo-Darwinian biology claims that the visible living world should be explained from the level of invisible, purely digital information [1]. Similarly, some branches of linguistics are approaching the language as a system based on a priori given principles and as completely detached from its source, namely, individual speech [2]. This postulate of the invariant nature of life or language enables the reduction of both phenomena into inert strings of letters - inner programs that have to be executed. This approach is, of course, very user-friendly and provides a platform for objective scientific research.

\section{Traditional problem of dichotomy and possible solution in developmental approaches}

De Saussure formulated the well-known and intuitively clear distinction between "langue" and "parole" [3]. This dichotomy was later reformulated by Chomsky as "competence and performance"; however, the traditional Saussurean meaning of "langue" was altered to a system of generative processes [4]. 
Some authors consider the speech (signals), the presence of syntax (grammar/structure) and the competence to transmit some meaning (semantics) as crucial components of human language faculty. Each of these components could be, according to Fitch [5], studied separately and can have different evolutionary history (and hence different explanatory principles).

I am questioning whether it is really so. And the question is not trivial to answer. To explore this problem, let us see an analogical debate in biology: the dichotomy of genotype and phenotype.

The traditional approach to investigating living world before the discoveries of modern genetics was built on identifying "forms" - special features characterizing a given "phenotype". Evolution of species was perceived as evolution of forms. Modern synthesis of Darwinian evolution and molecular genetics completely changed the level from which organisms should be studied: not from the level of variable bodies - phenotypes - but from the level of "stable" "genotype". It should be stressed, however, that the DNA molecule is actually also a body with a structure. The debate concerning what came first - genes or bodies - are of the same misleading manner as the question what is first, whether the language (as abstract system) or the speech (as individual bodily performance). What makes them "living" is the unity of the body and information. This fact is reflected each time during ontogenesis when a multicellular organism arises - usually as a clone - cell after cell. In any time point, it is in accordance with the inner information and with the actual state of the body. Modern science rather considers that the mystery of emergence of the living body will be fully explained as a set of procedures defined in the genome as soon as we are able to "read" the latter and developmental approaches are exiled from the mainstream. In the past decade, there have been attempts to get evolution and development back together in a new science called "evo-devo".

Back to language and speech: from acts of the individual speech arises the language, and this is reflected by a community of individuals developing within the constraints of the surrounding world. Language, in the broad sense, is a self-organizing structure analogically as life is. It is not given a priori but it is developing, in ontogeny, similarly as living beings - from the simple undifferentiated stage of early vocalizing, through babbling and first words, to complex adult utterances. Interestingly, in both the fields of linguistics and biology, there have appeared approaches that want to see life (or language) as a purely abstract and invariant entity, which can, of course, mutate and move in the world of physical constraints, but it cannot organize itself. Everything that happens on the level of the individual body must be only a result of an inner prescription, which can be finally described in a mathematical way as a property of digitalized text. These modern kinds of "preformism" in biology and linguistics probably do not want to omit the individual development from the evolution of life or language, but with an a priori statement of dividing the body/speech from its information/language, they just could not comprise it.

So what I want to say is that the language and the speech are analogous to the living being and its genetic memory. The word "language" (in the broad sense - seen in its unity with individual speech) can be perceived analogically as the "life" (the unity of genetic memory and individual bodies). There are no pre-formed invariants and hence there is no need of their designer. It is the life/language that designs itself through the evolutionary history.

\section{Previous view on language}

In current linguistic literature, it has been cited for a long time, according to Skinner [6], that language is something that should be just passively acquired by imitation. Development of language in infants is considered to be discontinuous with the pre-linguistic period, strictly separated from the following phase of first words and from the adult language: in other words, there is no connection between baby babbling and the language [7]. Finally, it is believed that the faculty of language came suddenly, by evolution, similar to, for instance, a mutation in a genome, which enabled people to develop the language. Therefore, the direction of language evolution is driven from inner competence to individual performance [4]. Language (or rather grammar) is an exclusively human possession. There cannot exist any continuity between the communication systems of human and non-human primates [8].

Such an a priori approach excludes the need for an ontogeny-phylogeny framework: language is but a passive, emergent object of neo-Darwinian selection and has no self-creating power; we cannot learn anything about the evolution of language from individual speech performance; non-human primates (and other animals) cannot possess a language in principle. Contrary to these "non-evolutionary" approaches, some authors such as StuddertKennedy [9] pointed out that language is not given as an a priori condition, but it is rather a consequence of development: a child not only acquires or internalizes the language, but he/she grows in it, because this process is implicit in the human developmental system. He argues that what we can see in speech development is the path from undifferentiated performance to differentiated "competence". 


\section{Methodology}

To validate the ontogeny-phylogeny framework in the context of language evolution, we should justify the following statements:

1. There is a universal conserved stage of language during the development of individuals, from which later specific languages differentiate.

2. Individual language development is continuous rather than discontinuous. (This means that there is continual transition between stages of speech development, and the pre-linguistic period is not divided from the period of first words.)

3. Individual language is not an imitation of adult language only, but it can participate actively in it.

4. There is a possible link between the communication of humans and non-human primates.

\section{Results and discussion}

\section{1) Conserved ontogenetic stage in language development}

Speech and the mental capacity of a newborn child are limited by the child's undeveloped brain and vocal apparatus, especially larynx, which - during the first half year of life - is in such a position that the baby can suck and breathe at the same time, but it does not allow the release of more than a few basic sounds and cries. At about the age of 6 months, the larynx descends down to the final position, and this enables the production of new and a larger repertoire of sounds.

Between the seventh and eighth months, children usually start to produce typical syllabic patterns. This stage is a period of so-called "canonical babbling". These utterances are released spontaneously and not induced by adults. For a child, it is a kind of exercise for developing the vocal apparatus - tongue, lips, muscles and jaws - the whole process is spontaneous and, at least in the first month of babbling, without any control from the side of the child. (A deeper description of this process is given by MacNeilage and Davis [10].)

Since the physiological constraints of our vocal apparatus are more or less the same for each individual, it looks logical that all babies will display similar patterns of canonical babbling.

For a long time, there was the common knowledge that deaf children do not produce babbling; this fact supported the notion that babbling is actually an imitation of adult speech. In fact, there were other studies showing that deaf children do babble, somewhat later than healthy children; they, however, need stimulation to do so [9]. Lynch et al. [11] show that even total deafness does not preclude canonical babbling. A child tracheotomised at the critical age in which canonical babbling usually occurs was not able to use vocal language appropriately, and the child displayed primitive babble-like patterns at a later age after decannulation, which suggests a crucial role of babbling in speech development [12]. Moreover, deaf children exposed to sign language since early childhood started to "babble" with their fingers [13]. These studies point out that the stage of canonical babbling is necessary for later development of language.

There are many studies supporting the fact that canonical babbling is a universal generative process characteristic for all children across the world:

Ecuadorean Quichua children were compared to children learning English in a previous study [13]. Babbling output was highly similar for the child groups: babbling by children learning Quichua and English demonstrated similar within-syllable patterns, as well as across-syllable variegation patterns, for consonants [14]. Other studies showed similar results: the speech production system plays a major role in acquisition of language, while the perception of ambient language is only minor at this stage [15]. Consonantal patterns of Korean and English children look to be similar (whereas vowel patterns seem to correspond more to ambient language) [16].

These studies show that the environment of ambient language plays the role of a stimulus, but the repertoire of patterns is influenced more by physiological constraints, and the general patterns in babbling are shared across the world.

\section{2) Continuity of an individual's language development}

If the period of canonical babbling was sharply separated from the period of first words and early child language, there should not be any connection between the sound patterns of babbling and early language. But the common experience of the majority is that the period of canonical babbling and the period of first words do overlap; moreover, 
those adopted from babbling sequences (mama, tata, baba, nene and so on) dominate among first words. Vihman et al. $[17,18]$ show that the patterns of first words and early language are rooted in the "pre-linguistic" period of canonical babbling, in contrast to the widely accepted and cited notion of Jakobson that babbling is sharply separated from language. Although processes leading to babbling are mostly unconscious, later on, early repetitive sequences are integrated into more complex performances. Children start to favour sounds of the ambient language and continuously pass from babbling to the production of the first words [19].

\section{3) Autonomy of language}

From these considerations, it seems to be clear that the period of canonical babbling represents something like a conserved stage in language development and that the transition from babbling to speech is a continuous process. As a direct consequence, it is obvious that the child itself takes part in adult language and in the active creation of new words, which are co-opted into adult language; therefore, language is not just an imitation but also a creative process, of course limited by physiological and perceptual constraints. As an evidence, we can refer to public research, such as by the International Language Web forum [29], which shows that the first baby words (family members, basic needs, emotions and so on) are rooted in repetitive sequences of canonical babbling and they are shared by many nationalities.

\section{4) Possible links between communication of humans and non-human primates}

There is a long-drawn-out debate about the similarities between communication in humans and in other living beings, especially apes, which are our closest evolutionary relatives. We do not want to recapitulate here the whole history of attempts at teaching apes (or other animals such as parrots) human language. Let us mention just two examples of research, which, in fact, demonstrate two opposite approaches to language, which have been discussed in this paper: Herbert Terrace's research on the chimpanzee Nim and Roger Fouts's research with the chimpanzee Washoe.

Attempts to teach apes vocal language were, of course, unsuccessful, because apes lack the appropriate vocal apparatus with descended larynx and they are not able to utter articulated words. Shrieks of apes are instinctive and controlled by the limbic system - it is hardly possible that there could develop articulated words and statements from it [20]. However, apes often use gestures in their natural environment. Allan and Beatrix Gardner [21] suggested that apes could possibly learn the American Sign Language (ASL). In 1966, according to this idea, the Gardners started to teach a young female chimpanzee - Washoe, and (almost in parallel) Herbert Terrace started his famous project with Nim. Although the leading idea of both projects was the same, there were crucial differences between the treatments of these chimpanzees. The Gardners brought up Washoe in the manner similar to how normal human children are brought up in their families, in a family house, surrounded by her adoptive parents, toys and a friendly environment. Nim was brought up in "standard" conditions of the research centre and, although he could move around with his guardians and had his "classes" with his instructors, his home was a cage. After 5 years of learning ASL, Nim was able to use basic words and phrases, but he did not develop a more-structured language. Terrace's general conclusion was that chimpanzees are not able to learn the language, they are only clever imitators of their instructors [22]. At the same time, the Gardners' project was taken over by Roger Fouts - originally a child psychologist - who devoted his whole life to the Washoe project, which is described in his book Next of Kin [20]. With a different approach to the project (as compared to Terrace), he got different results: Washoe was able to learn and use a vocabulary of about 350 words, and she had invented her own phrases, not only the learned ones. She was capable of abstraction and she talked about her emotions such as sadness or joy. Moreover, she taught ASL to her adoptive babies and other chimpanzees [23].

In the 1970s, debates about the origin of language (glottogenesis) were brought back to life, which were - for a whole century - exiled in the field of controversies or speculations [24]. One of the most developed theories was the "gestures first" theory of Hewes [25], who points to the universality of gestures and to the fact that by using only hands, without any syntax, one can express the relations between entities and even the time aspect (the past and the future). Although he solved the problem of how primitive grammar arose, he could not explain how the transition between gestural and vocal language was made [19, 24].

There is a crucial observation by Roger Fouts, who tried to explain the problem: simultaneously with his work with Washoe, he also worked with autistic children and he applied ASL teaching on them. After a few weeks of therapy, children started to use not only ASL but also normal vocal language. Fouts was surprised on seeing how the sensomotoric, visual and audio channels of autistic children are connected, as if the movements of hands 
stimulated articulated speech. Then, he put this information together with the information from neurology. Patients with aphasia (disturbance of the comprehension and formulation of language caused by dysfunction in specific brain regions) have problems also with hand movements and their coordination. This means that "speech demands precise and fine movements coordinated in a certain sequence. These movements are controlled by the same part of the brain". So, the transition between gestural and vocal language is not only possible, but it is even stimulated $[19,26]$.

Chimpanzees or other apes cannot, of course, undergo this transition because of the anatomy of their speech apparatus, but human ancestors equipped with a descended larynx could use gestural language with a primitive grammar, which stimulated them to do these "precise movements" also using tongue, jaws and other parts of their speech apparatus. The examples of Washoe and other "speaking" apes show us that these non-human primates have, in their sensomotoric and mental capacities, a predisposition for communication in gestural language and, although they did not develop human-like language, our common ancestor at least had this possibility.

\section{Conclusions}

Language development seems to be in accordance with the ontogeny-phylogeny framework. Language arises first from pre-linguistic communicative acts, gestures and instinctive cries, passes the period of canonical babbling (which seems to be a universal stage of all languages, as well as a necessary stage for further development) and continuously goes on to the production of first words. Hence, the language cannot be separated from its prelinguistic history and it could not appear in evolution suddenly as, for instance, with the result of a single mutation in the genome. Language is not only acquired, but children - as the individual language actors - can participate actively in speaking adult language. We are far from the need for any qualitative or quantitative comparison of human languages and genetic sequences (by mathematical or bioinformatics tools). We would rather like to point out that "language" and "life" share some common qualities arising from the fact that both of them are autonomous and self-creating entities, with their evolutionary history. There is an interesting parallel in the history of science: according to neo-Darwinian biology, we cannot study evolution of species from their morphology but only from the invariant level of their genetic information. Similarly, Chomskian linguistics claims that the individual ontogeny of speech cannot be relevant for studying language. These approaches serve life/language as rigid and a priori given invariants divided strictly from their living performances in the real world.

\section{Acknowledgment}

This work was supported by the Czech Ministry of Culture (grant NAKI II, DG18P02OVV065).

\section{References}

[1] Monod, J., 1971. Chance and necessity. New York: Alfred A. Knopf.

[2] Chomsky, N., 1968. Language and mind. New York: Harcourt, Brace \& World Inc.

[3] de Saussure, F., 1966. Course in General Linguistics. Edited by Charles Bally and Albert Sechehaye, in collaboration with Albert Riedlinger. Translated by Wade Baskin. New York: McGrawHill Book Company

[4] Chomsky, N., 1986. Knowledge of language. New York: Praeger.

[5] Fitch, W.T., 2005. The evolution of language: A comparative review. Biology and Philosophy, 20(23), 193-203.
[6] Skinner, B.F., 1957: Verbal behaviour. Acton, MA: Copley Publishing Group.

[7] Jakobson, R., 1941. Kindersprache, aphasie und allgemeine Lautgesetze. Uppsala: Linguistic Society of America. (Translated by Allan, R.K., Child language, aphasia, and phonologica universals. The Hague: Mouton, 1968.)

[8] Yang, Ch., 2013. Ontogeny and phylogeny of language. Proceedings of the National Academy of Sciences of the United States of America, 110(16), 6324-6327.

[9] Studdert-Kennedy, M., 1990. Language development from an evolutionary perspective. Haskins Laboratories Status Report on Speech 
Research, SR-101/102, 14-27.

[10] MacNeilage, P.F., Davis B., 1990. Acquisition of speech production: Frames, then content. In Jeannerod, M. (Ed.), Attention and performance 13: Motor representation and control. England: Lawrence Erlbaum Associates, Inc., pp. 453-476.

[11] M. P. Lynch, D. K. Oller, and M. Steffens,"Development of speech-like vocalizations in a child with congenital absence of cochleas: the case of total deafness," Applied Psycholinguistics 10, 315-333 (1989).

[12] Locke, J.L., Pearson, D.M., 1990. Linguistic significance of babbling: Evidence from a tracheotomised infant. Journal of Child Language, 17(1), 1-16. DOI: 10.1017/S0305000900013076.

[13] Newport, E.L., Meier, R.P., 1985. The acquisition of American sign language. In Slobin, D.I. (Ed.), The cross-linguistic study of language acquisition. Volume 1: The data. Vol. 2. Theoretical issues. Hillsdale, NJ, US: Lawrence Erlbaum Associates, Inc., pp. 881-938.

[14] Gildersleeve-Neumann, Ch.E., Davis, B.L., Macneilage, P F., 2013. Syllabic patterns in the early vocalizations of Quichua children. Applied Psycholinguistics, 34(01), 111-134. DOI: 10.1017/ S0142716411000634.

[15] Teixeira, E.R., Davis, B.L., 2002. Early sound patterns in the speech of two Brazilian Portuguese speakers. Language and Speech, 45(2), 179-204. DOI: 10.1177/00238309020450020401.

[16] Lee, S.A., Davis, B.L., Macneilage, P., 2010. Universal production patterns and ambient language influences in babbling: A cross-linguistic study of Korean- and English-learning infants. Journal of Child Language, 37(2), 293-318. DOI: 10.1017/S0305000909009532.

[17] Vihman, M.M., Ferguson, Ch.A., Elbert, M., 1986. Phonological development from babbling to speech: Common tendencies and individual differences. Applied Psycholinguistics, 7(1), 3-40. DOI: 10.1017/S0142716400007165.

[18] Vihman, M.M., Macken, M.A., Miller, R., et al.,
1985. From babbling to speech: A re-assessment of the continuity issue. Language, 61(2), 397-445. DOI: $10.2307 / 414151$.

[19] de Boysson-Bardies, B., Vihman, M.M., 1991. Adaptation to language: Evidence from babbling and first words in four languages. Language, 67(2), 297-319.

[20] Fouts, R., Miles, S.T., 1997. Next of kin: My conversations with Chimpanzees. Turtleback Books.

[21] Gardner R., A., Gardner B., T., Van Cantfort, T.E., 1989. Teaching sign language to Chimpanzees. State University of New York Press. Albany

[22] Terrace. H, 1987. Nim: A Chimpanzee Who Learned Sign Language. Columbia University Press.

[23] Fouts, R., Fouts, D.H., Van Cantfort, T.E., 1989. The infant Loulis learns signs from crossfostered chimpanzees. Teaching sign language to Chimpanzees, 280-292.

[24] Danesi, M., 1993. Vico, metaphor, and the origin of language. Bloomington: Indiana University Press.

[25] Hewes, G.W., 1973. Primate communication and the gestural origin of language (and comments and reply). Current Anthropology, 14(1-2), 5-24.

[26] Waters, G.S., Fouts, R., 2002. Sympathetic mouth movements accompanying fine motor movements in chimpanzees (Pan troglodytes) with implications toward the evolution of language. Neurological Research, 24(2), 174-180.

[27] Lieberman, P., 1984. The biology and evolution of language. Harvard University Press.

[28] Studdert-Kennedy, M., 1991. Language development from an evolutionary perspective. In Krasnegor, N.A., Rumbaugh, D.M., Schiefelbusch, R.L., et al. (Eds.), Biological and behavioral determinants of language development. Hillsdale, NJ, US: Lawrence Erlbaum Associates, Inc., pp. 5-28.

[29] WordReference.Com. Language forum- Babytalk vocabulary, available at: <http://forum. wordreference.com/showthread.php?t=1060391>. (Accessed September, 20 2014). 